\title{
Validity evidence of the Zulliger-CS in older adults with Parkinson's disease
}

\author{
Evidências de validade do Zulliger-SC em idosos com Doença de \\ Parkinson
}

\author{
Margarete RIEN ${ }^{1}$ \\ Silvana Alba SCORTEGAGNA ${ }^{1}$ \\ Jucelaine Bier Di Domenico GRAZZIOTIN' \\ Telma Elita BERTOLIN ${ }^{1}$
}

\begin{abstract}
The ethical principles of psychological assessment include the need to use reliable tests to meet the demands of the emerging population. Therefore, the present study sought to provide evidence of validity of the Zulliger Comprehensive System (Zulliger Test in the Comprehensive System) considering the constructs: self-perception and interpersonal relationships. A total of 61 older adults of both sexes participated in the study; 30 had Parkinson's disease (clinical group) and 31 were healthy (non-clinical group). The clinical group showed an increase in the following variables: Human detail $(p=0.02, d=0.50)$; Morbid responses $(p=0.025, d=0.62)$; Vista responses $(p=0.016, d=0.72)$, Food Responses $(p=0.021, d=0.61)$ and Decrease in human detail fictional $(p=0.012, d=-0.65)$ and in Personalized Responses $(p=$ $0.003, d=-0.48$ ). There was a positive relationship between the Zulliger Test in the Comprehensive System variables and age, income, and disease severity and a negative relationship between the Zulliger Test in the Comprehensive System variables and time since diagnosis. The results obtained confirm the validity of the Zulliger Test in the Comprehensive System and encourage further studies.
\end{abstract}

Palabras clave: Chronic disease; Old age; Projective techniques; Psychological assessment.

\section{Resumo}

Entre os princípios éticos da prática da avaliação psicológica destaca-se a necessidade do uso de testes fidedignos para responder às demandas da população emergente. Com esse propósito, buscou-se evidenciar a validade do Zulliger Sistema Compreensivo considerando os construtos autopercepção e relações interpessoais. Participaram do estudo 61 idosos, 30 com doença de Parkinson e 31 livres da doença, de ambos os sexos. O primeiro grupo apresentou aumento das variáveis de Detalhe humano $(p=0,02, d=0,50)$, Conteúdo mórbido $(p=0,025, d=0,62)$, Somatório de sombreado vista $(p=0,016, d=0,72)$, Alimento $(p=0,021, d=0,61)$ e Rebaixamento em detalhe para-humano $(p=0,012, d=$ $-0,65)$ e Respostas personalizadas $(p=0,003, d=-0,48)$. Houve associação positiva entre variáveis do Zulliger Sistema Compreensivo e idade, renda e severidade da doença e associação negativa com o tempo de diagnóstico. Os resultados ratificam a validade do Zulliger Sistema Compreensivo e estimulam novos estudos.

Keywords: Doença crônica; Velhice; Técnicas projetivas; Avaliação psicológica.

$\boldsymbol{\nabla V} \mathrm{v}$

${ }^{1}$ Universidade de Passo Fundo, Programa de Pós-Graduação Stricto Sensu em Envelhecimento Humano. BR 285, Caixa Postal 611, São José, 99052-900, Passo Fundo, RS, Brasil. Correspondência para/Correspondence to: S.A. SCORTEGAGNA. E-mail: <silvanalba@ upf.br> 
Approximately one in six people worldwide has some type of neurological disease. It is estimated that seven to 10 million people have Parkinson's Disease (PD) (National Parkinson Foundation, 2014), which is higher than the estimates of multiple sclerosis, amyotrophic lateral sclerosis, and muscular dystrophy (Bhimani, 2014). Most people with PD are age 60 years or older, but the disease can affect individuals in the third or fourth decade of life. The incidence and prevalence of this disease increase with age (National Parkinson Foundation, 2014).

The diagnosis of PD is established with the presence of four cardinal signs: resting tremor, muscular rigidity, bradykinesia, and postural instability (Berg, Marek, Ross, \& Poewe, 2012; Busse et al., 2012; Stern, Lang, \& Poewe, 2012). According to these authors, resting tremor is often localized in the hands, rigidity is characterized by an increased muscle tone triggered during passive movement, and bradykinesia is slowness of movements and difficulty in initiating voluntary movements, hindering the movement process and leading to mask-like face expression.

Following diagnosis, there is a progressive decrease in routine mobility activities such as walking, sitting, and standing and in the execution of Activities of Daily Living (ADL), such as personal hygiene, which can cause low self-esteem (Felippe et al., 2014; Queiroz, 2012; Stern et al., 2012). The cognitive impairments in PD, especially the Executive Function (EF) impairments, seem to be as disabling as the motor impairments (I. S. Campos-Sousa, Campos-Sousa, Ataíde Junior, Soares, \& Almeida, 2010), which increases the lack of interest and social withdrawal (Martinez-Martin, Rodriguez-Blazquez, Kurtis, \& Chaudhuri, 2011; Navarro-Peternella \& Marcon, 2012).

With the progression of the disease and increased dependence and difficulty to express themselves, PD patients usually accept help from others and exhibit passive behaviors (Queiroz, 2012). Additionally, they may be more vulnerable to developing anxiety, sadness, and depression, which are motivating factors that lead to frequent changes in social behavior and Quality of Life (QL) (Dawalibi, Anacleto, Witter, Goulart, \& Aquino, 2013; Martinez-Martin et al., 2011; Silva, Fernandes, \& Terra, 2014; Stern et al., 2012). This indicates the need for periodic psychological assessments.

Among reliable psychological assessment instruments is the Zulliger Test in the Comprehensive System (ZCS), which is a verbal reasoning test with good psychometric qualities and short completion time, approximately 20 minutes (Villemor-Amaral \& Primi, 2012). This may suggest that this test can be useful to contribute to the understanding of the psychological aspects of older adults with PD.

The Comprehensive System (CS) was developed in the United States by John Exner Jr. in the 1970s aiming at uniformity of administration, coding, and interpretation of the Rorschach, combining the contributions of the five major systems: Beck, Hertz, Piotrowzki, Rapapport/Shafer, Klopfer (Exner, 2003). The notoriety of the Rorschach Comprehensive System (RCS) has motivated researchers to carry out studies on the ZCS.

The ZCS has been used internationally. In Chile, it was administered to 19-60 year old adults (Vilches \& Olivos, 2004). In Brazil, most studies involved a population with a mean age of 39 years, among which is the study by Franco and VillemorAmaral (2012), who verified the incremental validity of Pfister in 20 drug addicted participants, 10 Brazilians and 10 French. The Brazilians showed interpersonal relationship problems evidenced by the decrease in Human content (Sum H), self-perception and Good Human Representations (GHR); increase in isolation, Morbid Responses (MOR), and Personalized Responses (PER).

Another study, carried out by Di DomenicoGrazziotin and Scortegagna (2013), investigated the validity of the ZCS in 40 healthy adults between 18 and 43 years of age. The variables GHR (good human representations), Pure $\mathrm{H}$ (pure-human), and Sum $\mathrm{H}$ correlated positively and significantly with communication, assertiveness, and self-control of aggressiveness factors of the Social Skills Inventory (SSI). 
The use of the ZCS with older adults is still incipient. The available studies are related to the Brazilian normative data published in 2009 (Franco, Cardoso, Villemor-Amaral, \& Primi, 2012) regarding the evidence for convergent and discriminant validity of the Pfister test (Franco \& Villemor-Amaral, 2009) and the evaluation of older adults with Chronic Kidney Disease (CKD) (Gregoleti \& Scortegagna, 2017). Investigating older people with CKD in a sample of 60 people, mean age of 73.1 years (Standard Deviation - SD = 5.8), Gregoleti and Scortegagna (2017), found that patients undergoing hemodialysis had interpersonal problems demonstrated by the decrease in the food responses $(\mathrm{Fd})(p=0.021, d=0.65)$, isolation ( $p$ $=0.006, d=0.61)$, and by the proportion of poor over good human representation responses (Poor Human Representations - PHR > Good Human Representations - GHR).

Among the groupings of the ZCS variables, self-perception and interpersonal relationships are particularly important in older patients with chronic diseases, especially PD. Self-perception refers to how a person views him/herself, i.e., an incomplete or more integrated view. The internalized images of oneself and others may be based on real or imaginary experiences and are related to self-esteem (Exner, 2003; Villemor-Amaral \& Primi, 2012). In older adults with PD, the disease limitations can increase feelings of loneliness, low self-esteem, cause depression (Felippe et al., 2014; Silva et al., 2014; Stern et al., 2012), and affect self-perception. The following variables are included in this grouping: MOR, vista responses (Sum V), anatomy (An), X-ray (Xy), and the ratio of whole or full human to the sum of whole human fictional, human detail, and human detail fictional $[H:(H)+H d+(H d)]$.

The variable MOR indicates signs of depression and negative self-perception. Sum $V$ is associated with self-criticism, damaged selfperception, and low self-esteem, with a tendency of the individual to have dissatisfaction, repulsion, introspection. The variables $A n$ and $X y$ are related to bodily concerns.

The assessment of interpersonal relationships is also extremely important. This construct provides information about the individual's attitudes, communication styles, interest in the social interactions, and real, partial, or fictitious identifications with people (Exner, 2003; VillemorAmaral \& Primi, 2012). The variables of this grouping include: human content (Sum H), Pure $H$, GHR, PHR, Shading-texture (Sum T), PER, and isolation.

The human content indicators $\mathrm{H},(\mathrm{H})+\mathrm{Hd}+(\mathrm{Hd})$ reflect the personal and interpersonal view of the human being (Exner, 2003; Weiner, 2003). The Pure $\mathrm{H}$ responses suggest the presence of a more whole interpersonal interest or a strong identification with people. On the other hand, the human detail $\mathrm{Hd}$ and human detail fictional $(\mathrm{Hd})$ suggest a partial, distrustful, and limited view of others. The variables GHR and PHR indicate the quality of the perceptions and human interaction representations (Viglione, Perry, Jarsak, Meyer, \& Exner, 2003).

Positive representations of self and others are identified in the GHR responses and the problematic, malevolent perceptions are identified in the PHR responses. The Fd responses show addictive behavior, and the Sum $T$ variable indicates need for human contact or reservation in interpersonal relationships. The high frequency of PER in adults is related to immaturity aspects and the need for self-justification. Therefore, considering that older adults with PD differ from healthy ones in both self-perception and interpersonal relationships, the following hypotheses were formulated:

Hypothesis 1 (H1). Older adults with PD will show self-perception changes. The Clinical Group (CG) will have a decrease in the responses of whole human content in relation to the sum of human fictional and human detail $[\mathrm{H}<(\mathrm{H})+\mathrm{Hd}+(\mathrm{Hd})]$ and an increase in the responses of morbid content ( $\uparrow M O R$ ), vista responses ( $\uparrow$ Sum $V$ ), and anatomy and $X$-ray $(\uparrow A n+X y)$ when compared to the Nonclinical Group (NCG). 
Hypothesis $2(\mathrm{H} 2)$. Older adults with PD will show interpersonal relationship difficulties. The CG will have a decrease in the responses of human content ( $\downarrow$ Sum H), Shading-texture (Sum $\mathrm{T}$ ) and in the proportion of good over poor human representations ( $\mathrm{GHR}<\mathrm{PHR}$ ) and an increase in food content responses ( $\uparrow \mathrm{Fd})$, isolation, and personalized responses ( $\uparrow P E R$ ) when compared to the NCG.

In the scope of the aforementioned discussions, the main objective of the present study was provide evidence of validity of the ZCS focusing on the self-perception and interpersonal relationships constructs in older adults with PD. In order to increase the strength of evidence of reliability, the relationship between the ZCS and the external variables age, income, disease severity, and time since diagnosis was also assessed.

\section{Method}

\section{Participants}

The non-random sample used in this study was composed of 61 older adults aged 60-90 years (Mean $-\mathrm{M}=71.93, \mathrm{SD}=7.54$ years); among which there were $50.81 \%$ females and $49.18 \%$ males, and $60.65 \%$ were married. Most of them had low level of education and income: 1-5 (37.70\%) and 6-10 years of schooling (31.14\%) and earned 3-5 (49.18\%) and 1-2 minimum wages (36.06\%), respectively. The participants lived in the state of Rio Grande do Sul, Brazil, in urban (68.85\%) and rural areas (31.14\%) and were distributed into CG and NCG.

The clinical group was composed of 30 individuals with PD; among which $63.33 \%$ were married, and $53.30 \%$ were self-employed. Their mean age was 72.13 years $(S D=8.14)$, mean level of education of 7.25 years $(S D=4.58)$, and their income was up to two minimum wages (66.66\%). They were patients in general hospitals and medical clinics. The inclusion criteria were as follows: individuals that had been diagnosed with PD for at least six months with mild to moderate impairment (stage I, II, III); the diagnosis was established by the neurologists responsible for the patient treatment. The NCG was composed of 31 healthy older adults who participated in senior center programs with mean age of 71.74 years $(S D=7.20)$; among which $58.06 \%$ were married, $58.06 \%$ were self-employed small business owners with mean level of education of 8.33 years (SD =5.62), and 74.19\% had earned 3-5 minimum wages.

Inclusion criteria were as follows: older adults who did not have cognitive decline and visual and hearing impairment and who accepted participating and completing the tests. These data were obtained through the administration of a socio-demographic and health protocol and the Mini-Mental State Examination (MMSE).

\section{Instruments}

Socio-demographic and Health Protocol: used to collect information on age, gender, marital status, level of education, socio-economic class, occupation, and health status and verify the inclusion/ exclusion criteria. For the patients with Parkinson's disease, information about the time since diagnosis and disease stage was also collected. The protocol consisted of 21 closed questions and was developed by the authors of this study.

Mini-Mental State Examination (MMSE) (M. F. Folstein, Folstein, \& McHugh, 1975): translated and validated in Brazil by Bertolucci, Brucki, Campacci, and Juliano (1994). This test was used to evaluate cognitive aspects and verify the inclusion and exclusion criteria for participation in the study. The test was composed of questions grouped into seven categories with a total score of 30 points. The cutoff points suggested by Brucki, Nitrini, Caramelli, Bertolucci, and Okamoto (2003) were used: (a) low educational level (1-4 years) - 21 points; (b) middle educational level (4-8 years) - 24 points; and (c) high educational level (over 8 years) - 26 points.

Zulliger Test in the Comprehensive System (ZCS) (Villemor-Amaral \& Primi, 2012): evaluates the 
structure and dynamics of personality. It consists of three cards; each one has a symmetrical and different inkblot. The task of responding to ambiguous stimuli encourages the respondents to use cognitive aspects such as attention, memory, perception, logical analysis, and underlying psychological processes such as feelings, concerns, experiences, and fantasies, which increase the value of this instrument for the evaluation of self-perception and interpersonal relationships (Perry, Viglione, \& Braff, 1992).

Two other studies were carried out in 2009 to verify the reliability of this test. Villemor-Amaral, Machado, and Noronha (2009) used the testretest reliability method and found that most of the indicators had values higher than 0.70 ( $p=$ 0.001). The other study used the inter-rater reliability agreement method to test the agreement between the evaluations of raters or judges (Muniz, Machado, Villemor-Amaral, \& Primi, 2012); the results showed satisfactory levels of agreement for most variables.

\section{Procedures}

Data collection started after obtaining authorization of the institutions involved and the study approval from the Research Ethics Committee (Protocol $n^{\circ}$ 669.104). The patients in the CG were invited to participate in the study by doctors and nurses, and those who showed interest were asked to sign the consent form. The MMSE, the socio-demographic and health protocol, and the ZCS were then individually administered at the hospitals and clinics or at the patients' homes in sessions that lasted approximately 80 minutes.

Concomitantly, older adults who participated in senior center programs were invited to participate in the study to form the NCG. Those who agreed to participate were asked to sign the consent form and respond to the MMSE, the sociodemographic and health protocol, and the ZCS. The instruments were individually administered at the senior centers in sessions lasting approximately 60 minutes.
In order to improve the reliability of the ZCS data, an inter-rater agreement study was carried out. Twenty-five percent of the protocols were randomly selected and sent to different raters to be rescored. Reliability was then estimated using the Kappa coefficient, which was $\geq 0.87$ for all variables of the test, indicating high reliability (Landis \& Koch, 1977).

\section{Data analysis}

The ZCS data were analyzed using the Statistical Package for Social Sciences, version 22.0. The Mann-Whitney $U$ test was used to compare the differences between the CG and NCG in terms of the socio-demographic variables income, gender, level of education, and marital status. The Student t-test was used to examine differences in age. Subsequently, the differences between the CG and NCG in terms of the variables of the self-perception and interpersonal relationship groupings of the ZCS were examined using the Mann-Whitney $U$ test. Test results with $p<0.05$ were considered statistically significant. Descriptive statistics was used to calculate the Mean and Standard Deviation, and the Cohen's $d$ was used to calculate the effect size; $d=0.20$ was considered a small or weak effect, $d=0.50$ a medium or moderate effect, and $d=$ 0.80 a large effect.

The relationships between the ZCS variables and age, income, level of education, disease severity, and time since diagnosis in the CG were examined using Spearman's correlation. The following variables were measured and characterized as categorical variables: time since diagnosis, 1-5 years, 6-10 years, and more than 11 years; disease severity, stages I, II, and III; and educational level, 1-5 years, from $6-10$ years, and $\geq 11$ years.

\section{Results}

The results were initially described with the comparisons between the ZCS variables using the Mann-Whitney $U$ test and the Cohen's d, followed 
by the results of the relationships between the ZSC indicators and the CG external variables - age, income, level of education, disease severity, and time since diagnosis, which were obtained using Spearman's correlation. Finally, the differences between the socio- demographic variables income, level of education, marital status, and age in the samples were described. Table 1 shows the comparisons between the selfperception and interpersonal relationship groupings in the CG and NCG.

Table 1

Comparison between the variables of self-perception and interpersonal relationship groupings of the ZCS

\begin{tabular}{|c|c|c|c|c|c|c|c|c|}
\hline \multirow{2}{*}{ Variables } & \multirow{2}{*}{$\begin{array}{l}\mathrm{CG}(\mathrm{n}=30) \\
(p 25-p 75)\end{array}$} & \multirow{2}{*}{$\begin{array}{c}\mathrm{NCG}(\mathrm{n}=31) \\
(p 25-p 75)\end{array}$} & \multirow{2}{*}{$p$} & \multicolumn{2}{|c|}{$C G(n=30)$} & \multicolumn{2}{|c|}{ NCG $(n=31)$} & \multirow{2}{*}{$d$} \\
\hline & & & & $M$ & $S D$ & $M$ & $S D$ & \\
\hline Pure $\mathrm{H}$ & $1.0(1.0-2.0)$ & $1.0(0.0-2.0)$ & 0.175 & 1.23 & 0.77 & 1.00 & 1.03 & 0.25 \\
\hline$(\mathrm{H})$ & $0.0(0.0-1.0)$ & $0.0(0.0-1.0)$ & 0.286 & 0.33 & 0.55 & 0.52 & 0.68 & 0.31 \\
\hline $\mathrm{Hd}$ & $0.0(0.0-1.3)$ & $0.0(0.0-1.0)$ & $0.002 *$ & 1.00 & 1.51 & 0.42 & 0.62 & 0.50 \\
\hline$(\mathrm{Hd})$ & $0.0(0.0-0.0)$ & $0.0(0.0-0.0)$ & $0.012 *$ & 0.00 & 0.00 & 0.23 & 0.50 & -0.65 \\
\hline Sum $\mathrm{H}$ & $2.0(1.0-4.3)$ & $1.0(0.0-2.0)$ & 0.132 & 2.57 & 1.81 & 2.16 & 1.53 & 0.24 \\
\hline MOR & $0.0(0.0-1.0)$ & $0.0(0.0-0.0)$ & $0.025^{*}$ & 0.50 & 0.78 & 0.13 & 0.34 & 0.62 \\
\hline Sum V & $0.0(0.0-0.0)$ & $0.0(0.0-0.0)$ & $0.016^{*}$ & 0.30 & 0.47 & 0.03 & 0.25 & 0.72 \\
\hline Sum T & $0.0(0.0-0.0)$ & $0.0(0.0-0.0)$ & 0.091 & 0.30 & 0.53 & 0.61 & 0.84 & -0.44 \\
\hline $\mathrm{Fd}$ & $0.0(0.0-0.3)$ & $0.0(0.0-0.0)$ & $0.021 *$ & 0.23 & 0.43 & 0.03 & 0.18 & 0.61 \\
\hline Social withdrawal & $1.0(0.0-2.3)$ & $1.0(0.0-3.0)$ & 0.970 & 1.57 & 1.50 & 1.61 & 1.61 & -0.02 \\
\hline PER & $0.0(0.0-0.0)$ & $0.0(0.0-1.0)$ & $0.003^{*}$ & 0.13 & 0.35 & 0.58 & 0.67 & -0.48 \\
\hline$A n+X y$ & $0.0(0.0-1.0)$ & $0.0(0.0-1.0)$ & 0.517 & 0.53 & 0.73 & 0.74 & 1.00 & 0.24 \\
\hline PHR & $0.5(0.0-2.0)$ & $1.0(0.0-2.0)$ & 0.367 & 1.20 & 1.65 & 1.16 & 1.04 & 0.03 \\
\hline GHR & $1.0(0.0-2.0)$ & $1.0(0.0-2.0)$ & 0.838 & 1.23 & 1.10 & 1.16 & 1.00 & 0.06 \\
\hline
\end{tabular}

Note: ZCS: Zulliger Test in the Comprehensive System; CG: Clinical Group; NCG: Non-Clinical Group.

ZCS variables: Pure H: whole human; (H): whole human fictional; Hd: Human detail; (Hd): Human detail fictional; Sum H: Human content; MOR: Morbid content; Sum V: Vista responses; Sum T: Shading-texture; Fd: Food responses; PER: Personalized Responses; An+Xy: Anatomy + X-ray; PHR: Poor Human Representations; GHR: Good Human Representations. Median values (p25 - p75); p: probability; * $p<0.05$; M: Mean; SD: Standard Deviation; $d$ : Cohen's d.

As can be seen from Table 1, there were statistically significant differences between the variables $(\mathrm{Hd})$, Hd, Sum V, Fd, PER, and MOR in the two groups. When compared to the NCG, the CG had a significant increase with moderate effect in the variables Hd, MOR, Sum V, and Fd. In contrast, the variables $(\mathrm{Hd})$ and PER had a significant decrease with moderate effect in the CG compared to that in the NCG. The results of the relationships between the ZCS variables and age, income, level of education, disease severity, and time since diagnosis in the CG are discussed below.

Table 2

Relationships between the ZCS variables and age, income, level of education, disease severity, and time since diagnosis in older adults with PD

\begin{tabular}{|c|c|c|c|c|c|}
\hline Variables & Age & Income & Level of education & Disease severity & Time since diagnosis \\
\hline \multicolumn{6}{|l|}{$\mathrm{R}$} \\
\hline$r_{s}:$ & 0.02 & -0.24 & 0.14 & -0.10 & -0.08 \\
\hline$p:$ & 0.912 & 0.208 & 0.469 & 0.595 & 0.688 \\
\hline \multicolumn{6}{|l|}{$\mathrm{H}$} \\
\hline$r_{s}:$ & -0.15 & 0.49 & 0.11 & -0.08 & -0.08 \\
\hline $\begin{array}{l}p: \\
(H)\end{array}$ & 0.431 & $0.006^{*}$ & 0.569 & 0.674 & 0.678 \\
\hline$r_{s}:$ & 0.09 & -0.13 & -0.13 & -0.01 & -0.17 \\
\hline p: & 0.640 & 0.509 & 0.485 & 0.949 & 0.365 \\
\hline \multicolumn{6}{|l|}{$\mathrm{Hd}$} \\
\hline$r_{\mathrm{s}}:$ & 0.04 & 0.05 & -0.16 & -0.04 & 0.09 \\
\hline \multicolumn{6}{|l|}{$(\mathrm{Hd})$} \\
\hline$r_{s}:$ & - & - & - & - & - \\
\hline$p:$ & - & - & - & - & - \\
\hline \multicolumn{6}{|l|}{ Sum $\mathrm{H}$} \\
\hline$r_{s}:$ & 0.06 & 0.13 & -0.15 & -0.09 & -0.04 \\
\hline
\end{tabular}




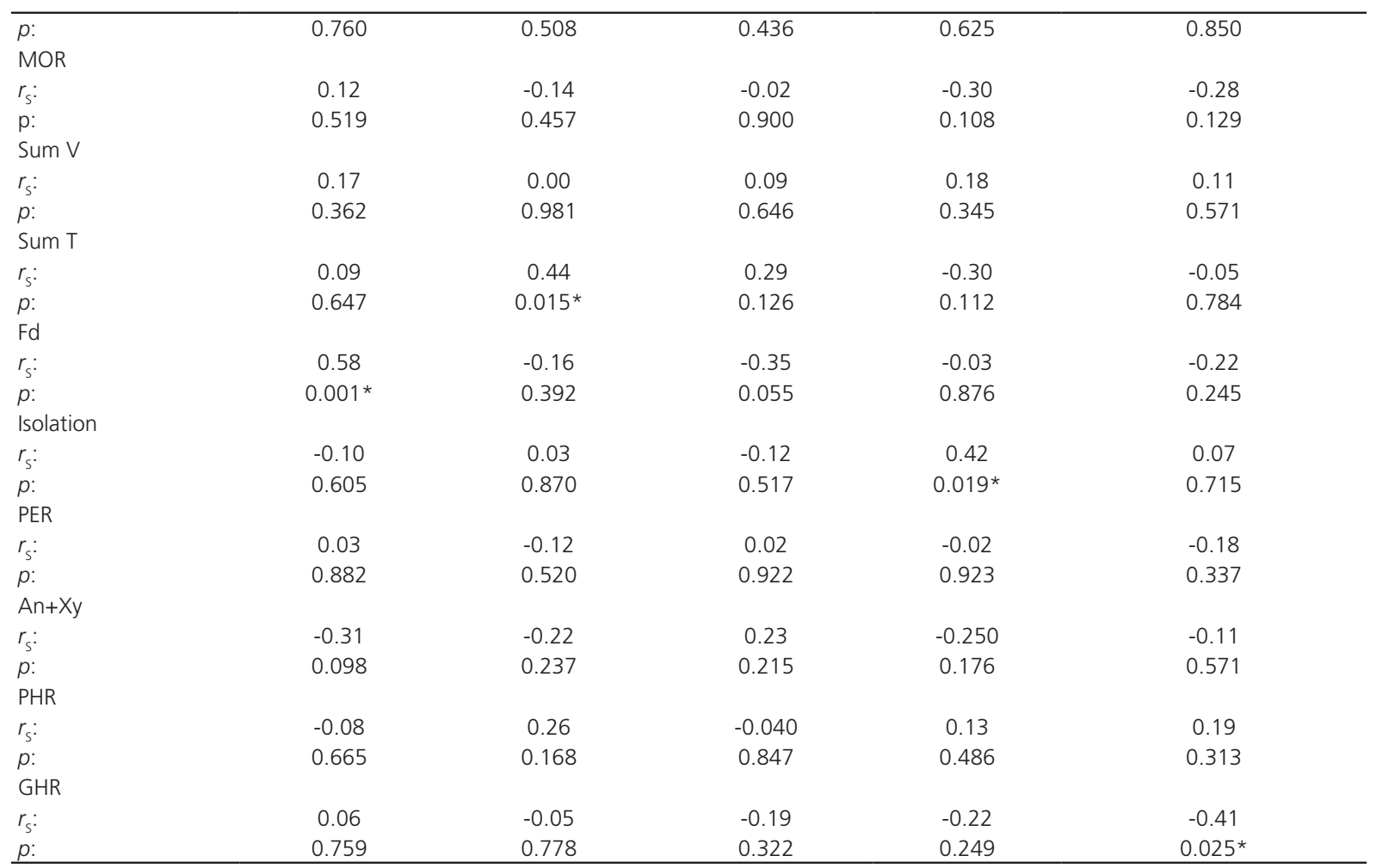

Note: ZCS: Zulliger Test in the Comprehensive System; ZCS variables: R: number of responses; H or Pure H: Whole human; (H): whole human fictional; Hd: Human detail; $(\mathrm{Hd})$ : Human detail fictional; Sum H: Human content; MOR: Morbid content; Sum V: Vista responses; Sum T: Shading-texture; Fd: Food responses; PER: Personalized responses; An+Xy: Anatomy + X-ray; PHR: Poor Human Representations; GHR: Good Human Representations; Spearman correlation: rs, p: probability, * $p<0.05$; Significant -: constant.

Table 2 shows statistically significant relationships between $H$, Sum $T$, Fd, social withdrawal, and GHR and the external variables. There were statistically significant moderate positive relationships between the variables $\mathrm{H}$ and Sum $T$ and income, suggesting that these indicators increase with higher incomes. There was a moderate positive relationship between $\mathrm{Fd}$ and age, indicating that this variable tends to increase in the older age groups. Similarly, there was a moderate positive relationship between the variable isolation and the degree of severity of the disease, pointing out that higher scores of this variable are related to later stages of PD. There was a moderate negative relationship between GHR and time since diagnosis, showing that this indicator decreases in individuals with longer time since PD diagnosis. The results of the differences between the socio-demographic variables of the samples studied (CG and NCG) are shown in Table 3.
Table 3

Socio-demographic characteristics of the samples studied

\begin{tabular}{|c|c|c|c|}
\hline \multirow{2}{*}{ Variables } & \multicolumn{2}{|c|}{ Group } & \multirow{2}{*}{$p$} \\
\hline & $C G(n=30)$ & $\operatorname{NCG}(n=31)$ & \\
\hline Age (years) & 72.1 & 71.7 & 0.841 \\
\hline \multicolumn{4}{|l|}{ Gender } \\
\hline Female & $15(50 \%)$ & $16(51.6 \%)$ & 0.217 \\
\hline Male & $15(50 \%)$ & $15(48.4 \%)$ & 0.900 \\
\hline \multicolumn{4}{|l|}{ Occupation } \\
\hline Self-employed & $16(53.3 \%)$ & $2(6.5 \%)$ & 0.001 * \\
\hline $\begin{array}{l}\text { Agricultural } \\
\text { worker }\end{array}$ & $8(26.7 \%)$ & $0(0 \%)$ & \\
\hline Teacher & $3(10.0 \%)$ & $1(3.2 \%)$ & \\
\hline Homemaker & $2(6.7 \%)$ & $4(12.9 \%)$ & \\
\hline $\begin{array}{l}\text { Small business } \\
\text { owner }\end{array}$ & $0(0 \%)$ & $18(58.1 \%)$ & \\
\hline Retired & $1(3.3 \%)$ & $4(12.9 \%)$ & \\
\hline $\begin{array}{l}\text { Public servant } \\
\text { Income (minimum } \\
\text { wages) }\end{array}$ & $0(0 \%)$ & $2(6.5 \%)$ & \\
\hline No income & $5(16.7 \%)$ & $0(0 \%)$ & 0.001 * \\
\hline $1-2$ & 15 (50\%) & $7(22.6 \%)$ & \\
\hline $3-5$ & $7(23.3 \%)$ & $23(74.2 \%)$ & \\
\hline $\begin{array}{l}\text { More than } 5 \\
\text { Level of education }\end{array}$ & $3(10 \%)$ & $1(3.2 \%)$ & \\
\hline Illiterate & $1(3.3 \%)$ & $0(0 \%)$ & $0.010 *$ \\
\hline $1-5$ years & $14(46.7 \%)$ & $9(29 \%)$ & \\
\hline $6-10$ years & 12 (40\%) & $7(22.6 \%)$ & \\
\hline$>11$ years & $3(10 \%)$ & $15(48.4 \%)$ & \\
\hline
\end{tabular}

Note: CG: Clinical Group; NCG: Non-Clinical Group. 
As can be seen from Table 3, there were no statistically significant differences between the variables marital status and age in the samples studied. However, there was a significant decrease in the variables income $(p=0.001)$ and level of education ( $p=0.010)$ in the CG when compared to the NCG, and there were statistically significant differences in the participants' occupation.

\section{Discussion}

The results obtained helped us better understand self-perception and interpersonal relationships in older adults with $\mathrm{PD}$, contributing to confirm the validity of the ZCS for effective psychological evaluation within this context. There were statistically significant differences in the self-perception grouping variables $\mathrm{Hd}$, $(\mathrm{Hd})$, sum $\mathrm{V}$, and MOR and in the interpersonal relationship indicators $\mathrm{Fd}$ and PER between the two groups. The relationships between the ZCS variables and the demographic variables age, income, and level of education that are related to the degree of severity of the disease and time since diagnosis improved our findings.

There was a significant increase in $\mathrm{Hd}(p$ $=0.002, d=0.50)$ and a decrease in $(\mathrm{Hd})(p=$ $0.0012, d=-0.65)$ in the CG compared to the NCG. Considering that there was a predominance of $(\mathrm{H})+\mathrm{Hd}+(\mathrm{Hd})$ responses in the control group, especially $\mathrm{Hd}$ over $\mathrm{H}$, it can be said that the older adults with PD investigated showed limited selfperception and perception of others and difficulties in interpersonal relationships that are characterized by anxiety, reservation, and distrust (Martinez-Martin et al., 2011; Silva et al., 2014; Stern et al., 2012). Distorted self-perception can lead to difficulties in expressing needs, thoughts, and feelings in an integrated manner thus affecting interpersonal relationships (Vilemor-Amaral \& Primi, 2012; Weiner, 2003). According to the views of Exner (2003), the results obtained show interest in the human being. However, the perception of others does not seem to be based on real experiences, but rather on retreat.
This result corroborates the findings of previous studies (Di Domenico-Grazziotin \& Scortegagna, 2013; Franco \& Villemor-Amaral, 2012). Examining the validity of the ZCS, Di Domenico-Grazziotin and Scortegagna (2013) found an increase in the $\mathrm{H}$ responses over human contents $(\mathrm{H})+\mathrm{Hd}+(\mathrm{Hd})$ in healthy people, which shows good communication skills, social resourcefulness, and interpersonal relationships. On the other hand, in a study on the incremental validity of the ZCS and Pfister, Franco and Villemor-Amaral (2012) found a decrease in the Sum $\mathrm{H}$ and absence of $\mathrm{H}$ in most protocols of patients with substance abuse problems, which indicates unrealistic ideas and attitudes and a lack of interest in interpersonal relationships.

Other interesting findings that deepen the understanding of self-perception changes are related to the significant increase in MOR $(p=0.025, d=$ $0.62)$ and Sum $V(p=0.0016, d=0.72)$ responses in the CG compared to NCG. These results suggest negative self-criticism and distorted self-perception in the patients with Parkinson's disease and indicate signs of depression, confirming the $\mathrm{H} 1$ proposed.

The disease challenges, especially those related to the loss of motor control, may cause feelings of hopelessness and low self-esteem (Felippe et al., 2014; Queiroz, 2012; Silva et al., 2014; Stern et al., 2012); thus, self-devaluation, self-criticism, and self-disapproval are commonly found (Silva et al., 2014; Stern et al., 2012). Previous studies have reported an increase in MOR in people with drug abuse problems (Franco \& Villemor-Amaral, 2012) and high Sum $V$ in patients with depression (Villemor-Amaral \& Machado, 2011), suggesting the presence of negative thoughts, attitudes, and feelings, evidencing the validity of the ZCS.

As for the interpersonal relationships, there was a significant increase in $\mathrm{Fd}(p=0.021, d=$ $0.61)$ and a significant decrease in PER ( $p=0.003$, $d=-0.48)$ in the CG compared to the NCG. This suggests dependent behavior, passivity, reduced self-determination, and less use of authoritarian self-defense in patients with PD, which could have been motivated by difficulties in executing ADL such 
as walking, driving, and personal hygiene (Felippe et al., 2014; Stern et al., 2012), which cause changes in social and family dynamics and require constant care (Bhimani, 2014; Silva et al., 2014).

These results confirm the $\mathrm{H} 2$ proposed in this study that older adults with PD would have interpersonal relationship problems. However, due to the decrease in PER, which contradicts the initial assumptions of this study, it can be said that older people with Parkinson's are not self-assertive in their interpersonal relationships. Some authors believe that PD patients voluntarily accept help and display less authoritarian and more passive behaviors because as the disease progresses, they tend to need more help and care (Bhimani, 2014; Queiroz, 2012).

Surprisingly, Gregoleti and Scortegagna (2017) found reduced Fd in patients undergoing hemodialysis, however, they reported a positive relationship between family and social support. In addition to the underlying differences between CKD and the PD and the psychosocial characteristics of caregiving environments, the relationship between the external variables and a more active social and family support may have contributed to minimize dependent behaviors. Conversely, Franco and Villemor-Amaral (2012) found an increase in PER in drug addicted people, indicating difficulties in accepting rules and help from others. These results point to the effectiveness of the ZCS to assess patients with chronic diseases, as shown in this study.

Important findings on the relationships between the ZCS indicators and the CG external variables age, income, disease severity, and time since diagnosis should be discussed. There was a significant moderate positive relationship between the variables $\mathrm{Fd}$ and age ( $\mathrm{r}_{\mathrm{o}}=0.58, p=0.001$ ), suggesting that the older the patient and presumably the more severe the disease, the more evident are the dependency characteristics, corroborating literature reports.

There was a significant moderate positive relationship between $\mathrm{H}$ and income ( $\mathrm{r}_{\mathrm{o}}=0.49, p=$ $0.385)$, Sum T and income ( $h_{0}=0.44, p=0.0015$ ), indicating that purchasing power may be a factor leading to a more integrated self-perception, desire for human contact, and more promising interpersonal relationships. Economic status can contribute to promote access to education, which tends to enhance cognitive resources (Bertolucci et al., 1994) and facilitate the development of better social skills.

With regard to the disease severity and isolation, the results show that the later the stage of the disease, the greater the social withdrawal (rho $=0.42, p=0.019$ ). It was observed that at later stages of the disease, individuals tend to isolate and distance themselves from social contact. With the progression of PD, there is a progressive decline in motor and cognitive functions that can provoke social withdrawal and more reclusive and introspective behaviors (Martinez-Martin et al., 2011; Silva et al., 2014; Stern et al., 2012).

There was a moderate negative relationship between the time since diagnosis and GHR ( $r h o=$ $-0.41, p=0.025)$. This result corroborates the findings discussed above and suggests that the shorter the time since diagnostic, the higher the possibility of older adults with PD to have good human representation and less conflicting interpersonal relationships.

In the comparison between the two groups, CG and NCG, six of the 14 ZCS variables analyzed showed statistically significant differences, providing relevant information about the understanding the psychological functioning in older adults with PD. Moreover, there were significantly smaller differences in the variables income $(p=0.001)$ and level of education $(p=0.010)$ in the CG when compared to NCG. Thus, it can be said that in older adults with PD, the variable level of education was not associated with the ZCS indicators and that the relationship between the variable income and the determinants $\mathrm{H}$ and Sum $\mathrm{T}$ showed no significant differences in the two groups. Therefore, the differences in the ZCS results found between the CG and NGC do not seem to be attributed to the socio-demographic variables age, gender, income, and level of education. 
In conclusion, the present study makes significant contributions including: (i) the evidence of validity of the ZCS to identify self-perception and interpersonal relationship problems in older adults with PD, distinguishing them from their healthy counterparts; (ii) the relationship between the ZCS indicators and external variables showed that with increasing age and time since diagnosis, social withdrawal and dependency increase. Better socioeconomic status and a shorter time since diagnosis were associated with the search for interpersonal relationships, ensuring the test reliability.

Finally, the results obtained should be interpreted with caution due to their limitations. Since a non-probability sampling technique with a subset of the population was used, the results cannot be generalized and causal inferences regarding the relationships between variables cannot be made. However, the use of a control group (NCG), the Kappa coefficient, and quantitative analysis methods increased data reliability and emphasized the importance of this study.

Therefore, the promising data presented encourage further studies. Considering that future research with older people with non-communicable diseases is a strong reality (Dawalibi et al., 2013), new studies could seek to provide evidence of validity of the ZCS regarding cognitive and affective constructs and concurrent and discriminant validity of this instrument for other variables such as social and family support in this emerging population.

\section{Contributors}

M. RIEN was responsible for designing and delineating the study, analysis and interpretation of the data, relevant critical writing of the content of the manuscript, for all aspects of the work, including the guarantee of its precision and integrity. S.A. SCORTEGAGNA participated in the design and delineation of the study, analysis and interpretation of the data and critical writing of the content of the manuscript, responsible for the final approval of the version to be published, including the guarantee of its precision and integrity. J.B.D. GRAZZIOTIN worked on the analysis and interpretation of the data and critical writing of the manuscript, including the guarantee of its precision and integrity. T.E. BERTOLIN participated in the design and of the study, and data analysis.

\section{References}

Bertolucci, P. H. F., Brucki, S. M. D., Campacci, S. R., \& Juliano, Y. (1994). O mini-exame do estado mental em uma população geral: impacto da escolaridade. Arquivos de Neuropsiquiatria, 52(1), 1-7.

Berg, D., Marek, K., Ross, G. W., \& Poewe, W. (2012). Defining at-risk populations for Parkinson's disease: Lessons from ongoing studies. Movement Disorders, 7, 656-665. https://doi.org/10.1002/mds.24985

Busse, K., Heilmann, R., Kleinschmidt, S., Abu-Mugheisib, M., Höppner, J., Wunderlich, C., ... Walter, U. (2012). Value of combined midbrain sonography, olfactory and motor function assessment in the differential diagnosis of early Parkinson's disease. Journal of Neurology Neurosurgery Psychiatry, 83(4), 441-447. https://doi. org/10.1136/jnnp-2011-301719

Bhimani, R (2014). Understanding the burden on caregivers of people with Parkinson's: A scoping review of the literature. Rehabilitation Research and Practice, 2014, ID 718527. https://doi.org/10.1155/2014/718527

Brucki, S. M. D., Nitrini, R., Caramelli, P., Bertolucci, P. H. F., \& Okamoto, I. H. (2003). Sugestões para o uso do Mini-Exame do Estado Mental no Brasil. Arquivos de Neuropsiquiatria, 61(3-B), 777-781. https://doi. org/10.1590/50004-282X2003000500014

Campos-Sousa, I. S., Campos-Sousa, R. N., Ataíde Junior, L., Soares, M. M. B., \& Almeida, K. J. (2010). Executive dysfunction and motor symptoms in Parkinson's disease. Arquivos de Neuropsiquiatria, 68(2), 246-251. https:// doi.org/10.1590/50004-282X2010000200018

Dawalibi, N. W., Anacleto, G. M. C., Witter, C., Goulart, R. M. M., \& Aquino, R. C. (2013). Envelhecimento e qualidade de vida: análise da produção científica da SciELO. Estudos de Psicologia (Campinas), 30(3), 393-403. https://doi.org/10.1590/\$0103-166X2013000300009

Di Domenico-Grazziotin, J. B., \& Scortegagna, S. A. (2013). Relacionamento interpessoal, produtividade e habilidades sociais: um estudo correlacional. Psico USF, 18(3), 491-500. https://doi.org/10.1590/S141382712013000300015

Exner, J. E., Jr. (2003). The Rorschach: A comprehensive system (Vol.I: Basic foundations). New York: Wiley \& Sons. 
Felippe, L. A., Oliveira, R. T., Garcia, M., Silva-Hamu, T. C. D., Santos, S. M. S., \& Christofoletti, G. (2014). Funções executivas, atividades da vida diária e habilidade motora de idosos com doenças neurodegenerativas. Jornal Brasileiro de Psiquiatria, 63(1), 39-47. https://doi.org/10.1590/00472085000000006

Folstein, M. F., Folstein, S. E., \& McHugh, P. R. (1975). "Mini-mental state". A pratical method for grading the cognitive state of patients for clinician. Journal of Psychiatric Research, 12(3), 189-198. https://doi. org/10.1016/0022-3956(75)900 26-6

Franco, R. R. C., Cardoso, L. M., Villemor-Amaral, A. E., \& Primi, R. (2012). Estudos de normatização, precisão e validade. In A. E. Villemor-Amaral \& R. Primi (Orgs.), Teste de Zulliger no sistema compreensivo ZSC: forma individual (pp.115-130). São Paulo: Casa do Psicólogo.

Franco, R. R. C., \& Villemor-Amaral, A. E. (2009). Validade concorrente entre provas de personalidade: Zulliger - SC e Pfister. Revista Psicologia e Saúde, 1(1), 50-59. https://doi.org/10.20435/pssa.v1i1.13

Franco, R. R. C., \& Villemor-Amaral, A. E. (2012). Validade incremental do Zulliger e do Pfister no contexto de toxicomania. Psico-USF, 17(1), 73-83. https://doi. org/10.1590/S1413-82712012000100009

Gregoleti, V., \& Scortegagna, S. A. (2017). O Zulliger com idosos em hemodiálise e a relação com variáveis externas. Paidéia, 27(66), 43-50.

Landis, J. R., \& Koch, G. G. (1977). The measurement of observer agreement for categorical data. Biometrics, 33(1), 159-174. https://doi.org/10.2307/2529310

Martinez-Martin, P., Rodriguez-Blazquez, R., Kurtis, M. M., \& Chaudhuri, K. R. (2011). The impact of non-motor symptoms on health-related quality of life of patients with Parkinson's disease. Movement Disorders, 26(3), 399-406. https://doi.org/10.1002/ mds. 23462

Muniz, M., Machado, M. A., Villemor-Amaral, A. E., \& Primi, R. (2012). Precisão do Zulliger no sistema compreensivo. In A. E. Villemor-Amaral \& R. Primi (Orgs.), Teste de Zulliger no sistema compreensivo ZSC: forma individual (pp.131-136). São Paulo: Casa do Psicólogo.

Navarro-Peternella, F. M., \& Marcon, S. S. (2012). Qualidade de vida de indivíduos com Parkinson e sua relação com tempo de evolução e gravidade da doença. Revista Latino-Americana de Enfermagem, 20(2), 384-391. https://doi.org/10.1590/S010411692012000200023
National Parkinson Foundation. (2014). Parkinson disease overview. Retrieved October 28, 2015, from http://www.parkinson.org/parkinson-s-disease.aspx

Perry, W., Viglione, D., Jr., \& Braff, D. (1992). The ego impairment index and schizophrenia: A validation study. Journal of Personality Assessment, 59(1), 165175. https://doi.org/10.1207/s15327752jpa5901_13

Queiroz, F. S. (2012). Autocuidado e qualidade de vida de idosas com Parkinson e disfunção miccional (Dissertação de mestrado não-publicada). Universidade Federal da Bahia, Salvador.

Silva, P. C. S., Fernandes, A. C. B. C., \& Terra, F. S. (2014). Avaliação da depressão e da capacidade funcional em idosos com doença de Parkinson. Revista de Enfermagem UFPE, 8(7),1920-1927. https://doi. org/10.5205/reuol.5963-51246-1-RV.0807201413

Stern, M. B., Lang, A., \& Poewe, W. (2012). Toward a redefinition of Parkinson's disease. Movement Disorders, 27(1), 54-60. https://doi.org/10.1002/ mds. 24051

Viglione, D. J., Perry, W., Jarsak, D., Meyer, G., \& Exner, J. E. (2003). Modifyng the Rorschach human experience variable to create the human representational variable. Journal of Personality Assessment, 8(1), 6473. https://doi.org/10.1207/S1532 7752JPA810106

Vilches, L., \& Olivos, S. (2004). Propuesta de parámetros referenciales para la utilización del test de Zulliger individual en selección de personal (Tese de doutorado não-publicada). Universidad de Chile, Santiago.

Villemor-Amaral, A. E., \& Machado, M. A. S. (2011). Indicadores de depressão do Zulliger no Sistema Compreensivo (ZSC). Paidéia, 21(48), 21-27. https:// doi.org/10.1590/S0103-863X2011000100004

Villemor-Amaral, A. E., \& Primi, R. (2012). O Teste de Zulliger no Sistema Compreensivo (ZSC): forma individual. São Paulo: Casa do Psicólogo.

Villemor-Amaral, A. E., Machado, M. A. S., \& Noronha, A. P. (2009). O Zulliger no Sistema Compreensivo: um estudo de fidedignidade. Psicologia Ciência e Profissão, 29(4), 656-671. https://doi.org/101590/ S1414-9893200900400002

Weiner, I. B. (2003). Principles of Rorschach interpretation. New Jersey: Lawrence Erlbaum Associates.

Received: December 10, 2015

Final version: August 23, 2016

Approved: September 27, 2016 